Preprints are preliminary reports that have not undergone peer review. They should not be considered conclusive, used to inform clinical practice, or referenced by the media as validated information.

\title{
A scoping review of 2019 Novel Coronavirus during the early outbreak period: Epidemiology, causes, clinical manifestation and diagnosis, prevention and control
}

\author{
Sasmita Poudel Adhikari \\ West China School of Public Health and West China Fourth Hospital \\ Sha Meng \\ West China School of Public Health and West China Fourth Hospital \\ Yuju Wu \\ West China School of Public Health and West China Fourth Hospital, Sichuan University \\ Yuping Mao \\ Department of Communication Studies, California State University, Long Beach, CA 90802, USA \\ Ruixue Ye \\ West China School of Public Health and West China Fourth Hospital, Sichuan University \\ Qingzhi Wang \\ West China School of Public Health and West China Fourth Hospital, Sichuan University \\ Chang Sun \\ West China School of Public Health and West China Fourth Hospital, Sichuan University \\ Sean Sylvia \\ Health Policy and Management, University of North Carolina at Chapel Hill, Chapel Hill, North Carolina, USA \\ Scott Rozelle \\ Freeman Spogli Institute for International Studies, Stanford University, California, USA \\ Hein Raat \\ Department of Public Health, Erasmus MC-University Medical Center Rotterdam, 3000 CA Rotterdam, The Netherlands \\ Huan Zhou ( $\sim$ zhouhuan@scu.edu.cn ) \\ West China School of Public Health and West China Fourth Hospital, Sichuan University
}

\section{Systematic Review}

Keywords: 2019-nCoV, epidemiology, causes, prevention and control, review

Posted Date: February 26th, 2020

DOI: https://doi.org/10.21203/rs.2.24474/v1

License: (c) (i) This work is licensed under a Creative Commons Attribution 4.0 International License. Read Full License 


\section{Abstract}

Background: The 2019-nCoV has been identified as the cause of an outbreak of respiratory illness in Wuhan, Hubei Province, China beginning in December 2019. This epidemic had spread to 19 countries with 11791 confirmed cases, including 213 deaths, as of January 31 , 2020 . The World Health Organization declared it as a Public Health Emergency of International Concern.

Methods: A scoping review of 65 research articles published until January 31, 2020 were analyzed and discussed for a better understanding of the epidemiology, causes, clinical diagnosis, prevention and control of this virus. The research domains, publishing dates, journal language, and authors' affiliations, as well as methodological characteristics were analyzed. All findings and statements that are mentioned regarding the outbreak in this review are based on published information as listed in the references.

Results: Most of the publications were in English language (89.23\%). The largest proportion of articles were related to causes (38.46\%) and majority (67.69\%), and were published by Chinese scholars. Research articles initially focused on causes while there was an increase of the articles related to prevention and control over time. Studies thus far have shown origination in connection to a seafood market in Wuhan, but specific animal association has not been confirmed. The reported symptoms include fever, cough, fatigue, pneumonia, headache, diarrhea, hemoptysis, and dyspnea. Preventive measures such as masks, hand hygiene practices, avoidance of public contact, case detection, contact tracing, and quarantines are being discussed for reducing the transmission. To date, no specific antiviral treatment is proven effective, hence, infected people primarily rely on symptomatic treatment and supportive care.

Conclusions: There has been a rapid surge in research in response to the outbreak of 2019-nCoV. During this early period, published research primarily explored the epidemiology, causes, clinical manifestation and diagnosis, as well as prevention and control of the novel coronavirus. Although these studies had relevance to the control of a public emergency, more high-quality research need to be conducted to provide valid and reliable ways to manage this kind of public health emergency in both short-and long-terms.

\section{Background}

The Coronavirus belongs to the family of virus that causes viral pneumonia including fever, breathing difficulty, and lung infection [1]. These viruses are common in animals worldwide, but very few cases of them are known to affect humans. The World Health Organization (WHO) used the term 2019 novel coronavirus (2019-nCoV) to refer to the coronavirus that was diagnosed from the lower respiratory tract of patients with pneumonia in Wuhan, China on 29 December, 2019 [2-4]. It was reported that the human infection of the virus originated from the local Huanan South China Seafood Market in Wuhan, Hubei Province, China [5]. Consequently, The Chinese Center for Disease Control and Prevention (China CDC) dispatched a rapid response team to accompany Hubei provincial and Wuhan city health authorities to conduct epidemiological and etiological investigations. The WHO reported that the outbreak of the coronavirus epidemic was associated with the marketplace, but no specific animal association has been identified [6]. Scientists immediately started to research the source of coronavirus. The first genome of 2019-nCoV was published by the research team led by Prof. Yong-Zhen Zhang, on January 10, 2020 [7]. Within one month, this virus spread quickly throughout China and globally during the Chinese New Year when there was high level of human mobility among Chinese. Although it is still early to predict the susceptible population, early patterns have shown a similar trend with Severe Acute Respiratory Syndrome (SARS) and Middle East respiratory syndrome (MERS) coronavirus. The susceptibility of the virus seems to be associated with age, biological sex and other health conditions [8]. 2019-nCoV has now been declared as Public Health Emergency of International Concern by WHO [9].

Given the spread of the new coronavirus and its impacts on human health, the research community has responded rapidly to the new virus and many preliminary research articles have already been published about this epidemic (Appendix Table). We conducted a scoping review to summarize and critically analyze all the published scientific articles regarding the new coronavirus in January 2020 . This review aims to provide the evidence of early findings on the epidemiology, causes, clinical diagnosis, as well as prevention and control of 2019-nCoV in relation to time, location and source of publication. This review can provide meaningful information for future research related to the topic and may support government decision-making on strategies to handle this public health emergency at the community, national and international levels.

\section{Methods \\ Study design}

A scoping review was conducted following the methodological framework suggested by Arksey and O'Malley [10]. The five stages followed for conducting this scoping review include: a) identifying clear research objective and search strategies, b) identifying relevant research articles, c) selection of research articles, d) extraction and charting of data, and e) summarizing, discussing, analyzing and reporting the results. 


\section{Literature search strategies}

Literature for this review was identified by searching the following online databases: bioRxiv, medRxiv, ChemRxiv, Google scholar, Pubmed, as well as CNKI and Wan Fang (the two primary databases for biomedical research in mainland China). These online databases contain archives of most English and Chinese biomedical journals. In addition, some white papers published online by the National Health Commission of China, National Center of Disease Prevention and Control, and WHO were also searched and included in the analysis. We searched scientific publications from 1 January to 31 January 2020. The search terms were 'nCoV', '2019 novel coronavirus', '2019-nCoV', 'novel coronavirus',

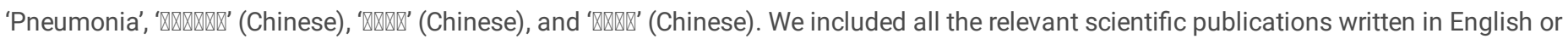
Chinese in the review. Commentary, reports and news articles were excluded from the analysis.

\section{Identification and selection of relevant studies}

Two researchers (YW and SPA), searched the literatures independently. The two sets of literature were compared. Disagreements on inclusion or exclusion of literature were resolved through discussion or, if necessary, including a third researcher (HZ) to make the decision. Duplicate articles were eliminated. Eventually, 65 unique academic publications were included in this analysis (Appendix Table). Figure 1 presents a Preferred Reporting Items for Systematic Reviews and Meta-Analyses (PRISMA) flow diagram showing the process of searching and selecting the research articles [11].

\section{Data extraction from the included studies}

After the articles were selected, data were extracted and recorded in the excel spreadsheet. The extracted data were date of publication, language of publication, title of article, name of journal, author's country and affiliation, study design, targets of study, sample size, study setting, data collection instrument, research domain, and key findings.

\section{Summarizing the findings}

Based on the main research objectives, articles were classified into one of the following four research domains: epidemiology, causes, clinical manifestation and diagnosis, prevention and control. 'Epidemiology' domain includes studies on the epidemic distribution (when, where, who); 'causes' domain includes studies on virology, pathogenesis, and transmission pattern; 'clinical manifestation and diagnosis' includes studies on the clinical features (signs and symptoms) and diagnosis; and 'prevention and control' domain includes studies on prevention, control and treatment measures.

Authors' affiliations were used to categorize the type of research collaboration. A publication was considered as deriving from 'inside China' when all affiliations of the authors were from China; a publication was considered as deriving from 'outside China' when all affiliations were outside China; a publication was considered as deriving from 'international collaboration' when at least one affiliation was from China, and one outside China. The research domains, publishing dates, journal language, authors' affiliations, as well as methodological characteristics were analyzed respectively. All findings and statements that are mentioned regarding the outbreak in this review are based on published information as listed in the references.

\section{Results And Disucssion Characteristics of published studies}

Among the 65 research articles included in the analysis, more than 31 are on preprint servers, and 34 are published in peer-reviewed journals, including The Lancet and the New England Journal of Medicine. Most of the publications ( $n=58,89.23 \%)$ are in English and few ( $=7,10.77 \%$ ) are in Chinese. Around $75.86 \%$ of English language publications focus on epidemiology and causes, while $85.71 \%$ of Chinese papers focus on prevention and control (Table 1).

As shown in figure 2, academic publications are distributed across the following research domains: epidemiology, causes, clinical manifestation and diagnosis, as well as prevention and control. The largest portion of the papers $(n=25,38.46 \%)$ are related to causes, followed by papers on epidemiology ( $n=19,29.23 \%$ ), while $18.46 \%$ examined prevention and control and $13.85 \%$ reported clinical manifestations and diagnosis. Initially, there were more research articles focused on causes of the virus, yet prevention and control studies have gradually increased over time (Figure 3). The majority of the articles $(n=44,67.69 \%)$ were published by Chinese scholars whereas $29.23 \%(n=19)$ articles were from scholars outside of China, and few $(n=2,3.08 \%)$ are based on international collaborative research by scholars from different countries (Table 2 ). 
Table 1 Breakdown of 2019-nCoV research articles by language in January 2020

\begin{tabular}{|lllllll|}
\hline Research & \multicolumn{2}{l}{ English literature } & \multicolumn{2}{l}{ Chinese literature } & \multicolumn{2}{l|}{ Total } \\
\cline { 2 - 7 } domains & $\mathrm{n}$ & $\%$ & $\mathrm{n}$ & $\%$ & $\mathrm{n}$ & $\%$ \\
Epidemiology & 19 & 32.76 & 0 & 0.00 & 19 & 29.23 \\
\hline Causes & 25 & 43.10 & 0 & 0.00 & 25 & 38.46 \\
\hline Clinical manifestation and diagnosis & 8 & 13.79 & 1 & 14.29 & 9 & 13.85 \\
\hline Prevention and control & 6 & 10.34 & 6 & 85.71 & 12 & 18.46 \\
\hline Total & 58 & 89.23 & 7 & 10.77 & 65 & 100.00 \\
\hline
\end{tabular}

Methodological characteristics of those publications were analyzed. The majority of the articles are based on mathematical modeling (44.62\%) followed by cross -sectional study designs (18.46\%). Around half of the research include targeted population (49.23\%) for their analysis followed by species (36.92\%). Among the 32 articles with population as the target of study, $34.38 \%$ had a sample size less than $10,31.25 \%$ were conducted in hospital setting, and 50\% used secondary data. Quality control activities for data collection were mentioned in $56.25 \%$ of the population study (Table 3).

Table 2 Breakdown of 2019-nCoV research articles by type of collaboration in January 2020

\begin{tabular}{|c|c|c|c|c|c|c|c|c|}
\hline \multirow{3}{*}{$\begin{array}{l}\text { Research } \\
\text { domains }\end{array}$} & \multirow{2}{*}{\multicolumn{2}{|c|}{$\begin{array}{l}\text { Inside } \\
\text { China }\end{array}$}} & \multirow{2}{*}{\multicolumn{2}{|c|}{$\begin{array}{l}\text { Outside } \\
\text { China }\end{array}$}} & \multirow{2}{*}{\multicolumn{2}{|c|}{$\begin{array}{l}\text { International } \\
\text { Collaboration }\end{array}$}} & \multirow{2}{*}{\multicolumn{2}{|c|}{ Total }} \\
\hline & & & & & & & & \\
\hline & $\mathrm{n}$ & $\%$ & $\mathrm{n}$ & $\%$ & $\mathrm{n}$ & $\%$ & $\mathrm{n}$ & $\%$ \\
\hline Epidemiology & 8 & 18.18 & 9 & 47.37 & 2 & 100.00 & 19 & 29.23 \\
\hline Causes & 17 & 38.64 & 8 & 42.11 & 0 & 0.00 & 25 & 38.46 \\
\hline Clinical manifestation and diagnosis & 8 & 18.18 & 1 & 5.26 & 0 & 0.00 & 9 & 13.85 \\
\hline Prevention and control & 11 & 25.00 & 1 & 5.26 & 0 & 0.00 & 12 & 18.46 \\
\hline Total & 44 & 67.69 & 19 & 29.23 & 2 & 3.08 & 65 & 100.00 \\
\hline
\end{tabular}




\begin{tabular}{|c|c|c|c|}
\hline Characteristics & Categories & $\mathrm{n}$ & $\%$ \\
\hline \multirow{6}{*}{$\begin{array}{l}\text { Study design } \\
(n=65)\end{array}$} & Cross-sectional studies & 12 & 18.46 \\
\hline & Mathematical modeling & 29 & 44.62 \\
\hline & Molecular studies & 10 & 15.38 \\
\hline & Diagnostic studies & 2 & 3.08 \\
\hline & Review & 3 & 4.62 \\
\hline & Theoretical study & 9 & 13.85 \\
\hline \multirow{6}{*}{$\begin{array}{l}\text { Targets of study } \\
(n=65)\end{array}$} & Population & 32 & 49.23 \\
\hline & Patients & 22 & 33.85 \\
\hline & General population & 6 & 9.23 \\
\hline & Healthcare workers & 4 & 6.15 \\
\hline & Species (virus structure, gene sequence) & 24 & 36.92 \\
\hline & Other & 9 & 13.85 \\
\hline \multicolumn{4}{|c|}{ Study related to population $(n=32)$} \\
\hline \multirow[t]{5}{*}{ Sample size } & $1-10$ & 11 & 34.38 \\
\hline & $11-50$ & 5 & 15.63 \\
\hline & $51-100$ & 3 & 9.38 \\
\hline & $>100$ & 3 & 9.38 \\
\hline & Not specified & 10 & 31.25 \\
\hline \multirow[t]{6}{*}{ Study setting } & Laboratory & 2 & 6.25 \\
\hline & Hospital & 10 & 31.25 \\
\hline & Community & 0 & 0.00 \\
\hline & Hospital and community & 0 & 0.00 \\
\hline & Not specified & 20 & 62.50 \\
\hline & Questionnaire & 7 & 10.77 \\
\hline \multirow[t]{5}{*}{ Data-collection instrument* } & Biological specimen collection & 1 & 3.13 \\
\hline & Physical examinations & 0 & 0.00 \\
\hline & Environmental sample & 0 & 0.00 \\
\hline & Hospital, medical, or exposure records & 14 & 43.75 \\
\hline & Secondary data & 16 & 50.00 \\
\hline \multirow{3}{*}{$\begin{array}{l}\text { Quality-control activities } \\
\text { for data collection }\end{array}$} & Indicated in the article & & \\
\hline & Not specified & 14 & 56.25 \\
\hline & & 18 & 43.75 \\
\hline
\end{tabular}

* Percentages in this section do not add up to $100 \%$ because multiple answers were possible. 


\section{Research domains}

\section{Epidemiology}

On 29 December 2019, the first four cases of an acute respiratory syndrome of unknown etiology among people linked to a seafood market ("wet market") were reported in Wuhan city, Hubei province, China [2]. Research is underway to understand more about transmissibility, severity, and other features associated with 2019-nCoV [3]. It appeared most of the early cases had contact history with the original seafood market [2, 12-14]. Soon, the secondary source of infection was found to be human-to-human transmission among close contacts. There was an increase of infected people with no history of exposure to wildlife or visiting Wuhan, and multiple cases of infection were detected among medical professionals [2, 14-17]. The 2019-nCoV infection occurs through exposure to the virus, and both the immunosuppressed and normal population appear susceptible. Some studies have reported an age distribution of adult patients between 25 and 89 years old. Most adult patients are between 35 and 55 years old. There are fewer identified cases among children and infants $[14,18]$. A study on early transmission dynamics of the virus reports the median age of patients to be 59 years, ranging from 15 to 89 years, with the majority (59\%) being male [2]. In this publication it was suggested that the population at most risk may be people with poor immune function such as older people and people with renal and hepatic dysfunction [2]

The 2019-nCoV has been found to have higher levels of transmissibility and pandemic risk than the SARS-CoV as the effective reproductive number (R) of 2019-nCoV (2.9) is estimated to be higher than the reported effective reproduction number (R) of SARS (1.77) at the early stage [15]. The average incubation duration of 2019-nCoV were estimated to be $4.8 \pm 2.6$, ranging from 2-11 days [15] and 5.2 days (95\% Confidence interval, 4.1 to 7) [2]. The latest guidelines from Chinese health authorities mentioned an average incubation duration of 7 days, ranging from 214 days [19].

In China, 11791 cases were confirmed and 17988 were suspected cases in 34 provinces as of 24:00, January 31, 2020 (Figure 4) [20]. The studies mentioned a relatively quick spread of the $2019-\mathrm{nCoV}$, and also reported the spread to several other countries after its outbreak in China; there were 213 deaths reported globally on January 31, 2020 [21]. Confirmed cases were reported in the following 19 countries outside of China: Australia (9), Canada (3), Cambodia (1), France (6), Finland (1), Germany (5), India (1), Italy (2), Japan (14), Nepal (1), Malaysia (8), Philippines (1), Republic of Korea (11), Singapore (13), Sri Lanka (1), Thailand (14), United States of America (6), United Arab Emirates (4) and Vietnam (5) (Figure 5) [21].

\section{Causes}

Virology and Pathogenesis

Coronaviruses are enveloped single-stranded RNA viruses that are zoonotic in nature and cause symptoms ranging from those similar to the common cold to more severe respiratory, enteric, hepatic and neurological symptoms [5, 22]. Other than 2019-nCoV, there are six known coronaviruses in human: HCoV-229E, HCoV-OC43, SARS-CoV, HCoV-NL63, HCoV-HKU,1 and MERS-CoV $[2,19,23,24]$. Coronavirus has caused two large scale pandemics in the last two decades: SARS $[25]$ and MERS $[12,26]$.

To detect the infection source of 2019-nCoV, the China CDC researchers collected 585 environmental samples from the Huanan Seafood Market in Wuhan, Hubei Province, China on January 1 and January 12, 2020. They detected 33 samples containing 2019-nCoV and indicated that it originated from wild animals sold in the market [27]. Then, researchers used the lung fluid, blood, and throat swab samples of 15 patients to conduct laboratory tests. These laboratory tests found the virus-specific nucleic acid sequences in the sample, which has a different coronavirusspecific nucleic acid sequences from known human coronavirus species. Laboratory results also indicated that 2019-nCoV is similar to some of the beta $(\beta)$ coronaviruses genera identified in bats $[12,18,28]$, which is situated in a group of SARS/ SARS-like CoV [12].

To conduct next-generation sequencing from bronchoalveolar lavage fluid and cultured isolates, researchers enrolled nine inpatients with viral pneumonia and negative in common respiratory pathogens in Wuhan. The results of this next-generation sequencing indicated that 2019-nCoV was more distant from SARS-CoV (with about 79\% sequence identity) and MERS-CoV (with about $50 \%$ sequence identity) than from two batderived SARS-like coronaviruses- bat-SL-CoVZC45 (with $87.99 \%$ sequence identity) and bat-SL-CoVZXC21 (with $87.23 \%$ sequence identity) [29]. Studies also reported that 2019-nCoV S-protein supported strong interaction with human ACE2 molecules despite its sequence diversity with SARS-CoV $[12,30]$.

\section{Transmission pattern}

Many domestic and wild animals, including camels, cattle, cats, and bats, may serve as hosts for coronaviruses [19]. It is considered that, generally, animal coronaviruses do not spread among human beings [3]. However, there are exceptions, such as SARS and MERS, which are mainly spread though close contact with infected people via respiratory droplets from cough or sneezing. With regard to 2019-nCoV, early patients were reported to have some link to the Huanan Seafood Market in Wuhan, China, suggesting that these early infections were due to 
animal-to-person transmission. Soon, more cases were reported among medical staff and others with no history of exposure to that market or visiting Wuhan, which was taken as an indication for human-to-human transmission [2, 4, 15-17].

The latest guidelines from Chinese health authorities [19, 31], described three main transmission routes for the 2019-nCoV: 1) direct transmission, 2) aerosol transmission, 3) contact transmission. Direct transmission are reported to occur when respiratory droplets (as produced when an infected person coughs or sneezes) are ingested or inhaled by individuals nearby in close proximity; Aerosol transmission may occur when respiratory droplets mix into the air, forming aerosols and causing infection when inhaled into the lungs; and Contact transmission may occur when a subject touches a surface or object contaminated with the virus. According to the literature, individuals could be infected when they subsequently touch their mouth, nose, or, possibly, eyes [19, 31]. In addition to these three routes, one study also indicated the digestive system as a potential transmission route for 2019-nCoV infection. Since patients had abdominal discomfort and diarrhea symptoms, researchers analyzed 4 datasets with single-cell transcriptomes of digestive system and found that ACE2 was highly expressed in absorptive enterocytes from ileum and colon [32].

\section{Clinical manifestation and diagnosis}

The complete clinical manifestation is not clear yet, as the reported symptoms range from mild to severe, sometimes even resulting in death [3]. The most commonly reported symptoms are fever, cough, myalgia or fatigue, pneumonia and complicated dyspnea, whereas less common reported symptoms include headache, diarrhea, hemoptysis, runny nose, and phlegm-producing cough [3, 16]. Patients with mild symptoms were reported to be usually recovered after 1 week while severe cases were reported to experience progressive respiratory failure due to alveolar damage from the virus, which may lead to death [13]. Cases resulting in death were primarily middle-aged and elderly patients with pre-existing diseases (tumor surgery, cirrhosis, hypertension, coronary heart disease, diabetes, and Parkinson's disease) [13]. Case definition guidelines mention the following symptoms: fever, decrease in lymphocytes and white blood cells, new pulmonary infiltrates on chest radiography, and no improvement in symptoms upon three days of antibiotics treatment [2].

For patients with suspected infection, the following procedures have been suggested for diagnosis: performing real-time fluorescence (RT-PCR) to detect the positive nucleic acid of 2019-nCoV in sputum, throat swabs, and secretions of the lower respiratory tract samples [13, 14, 31].

\section{Prevention and Control}

Prevention and control strategies and methods are reported at three levels: national level, case-related population level, and general population level. At the national level, the National Health Commission of the People's Republic of China issued the "No.1 announcement" on January 20, 2020, which officially included the 2019-nCoV into the management of class B legal infectious diseases, and allowed for class A infectious diseases preventive and control measures to be implemented [33]. Under this policy, medical institutes can adopt isolation treatment and observation protocols to prevent and control the spread of the 2019-nCoV. On January 22, 2020, the National Health Commission published national guidelines for the prevention and control of 2019-nCoV for medical institutes to prevent the nosocomial infection [34]. On January 28, 2020, the National Health Commission issued protocols for rapid prevention and control measures in order to effectively contain the spread of epidemic through a "big isolation and big disinfection" during the Chinese Spring Festival [35]. National-level strategies have also been issued with targeted measures for rural areas (issued on January 28, 2020) and the elderly population (issued on January 31, 2020) [36, 37]. Several public health measures were mentioned that may prevent or slow down the transmission of the 2019-nCoV; these include case isolation, identification and follow-up of contacts, environmental disinfection, and use of personal protective equipment [38].

To date, no specific antiviral treatment has been confirmed to be effective. Regarding infected patients with 2019-nCoV, it has been recommended to apply appropriate symptomatic treatment and supportive care $[3,16]$. Studies have also explored the prevention of nosocomial infection and psychological health issues associated with the 2019-nCoV. A series of measures have been suggested to reduce nosocomial infection, including knowledge training for prevention and control, isolation, disinfection, classified protection at different degrees in infection areas, and protection of confirmed cases $[18,38,39]$. Concerning psychological health, some suggested psychological intervention for confirmed cases, suspected cases, and medical staffs $[18,40]$.

For the general population, at this moment there is no vaccine preventing 2019-nCoV. The best prevention is to avoid being exposed to the virus [41]. Airborne precautions and other protective measures have been discussed and proposed for prevention. Infection preventive and control (IPC) measures that may reduce the risk of exposure include the following: use of face masks; covering coughs and sneezes with tissues (or flexed elbow) that are then safely disposed of; regular hand washing with soap or disinfection with hand sanitizer containing at least $60 \%$ alcohol (if soap and water is not available); avoidance of contact with infected people and keeping the distance as much as possible; and the refrain from touching eyes, nose, and mouth with unwashed hands [3].

WHO discussed the detailed advice on the use of face masks in the community, during care at home, and in the health care settings in 2019nCoV [42]. In this document, health care workers are recommended to use the particulate respirator such as certified N95 or FFP2 when performing aerosols generating procedures, and to use medical masks while providing any care to suspected or confirmed cases. According to

Page $7 / 13$ 
this document, individuals with respiratory symptoms are advised to use medical masks both in health care and home care settings properly following the infection prevention guidelines. According to this advice, in the community, individual without respiratory symptoms do not require a medical mask. Individuals should cover nose and mouth with tissues or flexed elbow while coughing and sneezing. Regular hand hygiene is recommended. Proper use and disposal of masks are important to avoid any increase in risk of transmission [42].

In addition to articles published in research journals, the China CDC published a guideline to raise awareness of the prevention and control of 2019-nCoV among the general population. This guideline contains plenty information on the 2019-nCoV itself and its prevention. The key messages of the guideline include: the causes of 2019-nCoV, how to choose and wear face masks, proper hand washing habits, preventive measures at different locations (e.g., at home, on public transportation, and in public space), disinfection methods, and medical observation at home [43]. In addition to scientific knowledge on ways to handle the 2019-nCoV outbreak, the guideline also suggests ways to eliminate panic among the general population [43]. To date, no specific antiviral treatment has been confirmed to be effective. Regarding infected patients with 2019-nCoV, it has been recommended to apply appropriate symptomatic treatment and supportive care $[3,16]$.

\section{Strength And Limitation Of The Study}

The review applied a systematic and rigorous search strategy to retrieve all the relevant articles according to the research objectives. Our study only focused on the articles published either on English or Chinese language during early outbreak period. It cannot reflect the entire body of research on 2019-nCoV worldwide.

\section{Conclusions}

This study shows a holistic picture of the current research in response to the outbreak of 2019-nCoV. During this early period, studies have been published exploring the epidemiology, causes, clinical manifestation and diagnosis, as well as prevention and control of the novel coronavirus. Thus far, most studies have focused on the epidemiology and potential causes. Studies exploring prevention and control measures have begun to gradually increase. Studies providing evidence on prevention and control measures are urgently needed to minimize the impact of the outbreak. Government agencies have quickly incorporated recent scientific findings into public policies at community, regional, and national levels to slow down and/or prevent the further spread of the 2019-nCoV. We recommend conducting more research to provide valid and reliable ways to manage this kind of public health emergency in both short- and long- term.

\section{List Of Abbreviations}

2019- nCoV: 2019 novel coronavirus

ACE2: Angiotensin Converting Enzyme 2

CDC: Center for Disease Control

IPC: Infection prevention and control

MERS: Middle East Respiratory Syndrome

PRISMA: Preferred Reporting Items for Systematic Reviews and Meta-Analyses

SARS: Severe Acute Respiratory Syndrome

WHO: World Health Organization

\section{References}

1. Wuhan Municipal Health and Health Commission's Briefing on the Current Pneumonia Epidemic Situation in Our City. 2020 [http://wjw.wuhan.gov.cn/front/web/ showDetail/2019123108989] Accessed on 1 February 2020.

2. Li Q, et al. Early Transmission Dynamics in Wuhan, China, of Novel Coronavirus-Infected Pneumonia. The New England Journal of Medicine. 2020; [DOI: 10.1056/NEJMoa2001316].

3. 2019 Novel Coronavirus, Wuhan, China. 2020. [https://www.cdc.gov/coronavirus/2019-nCoV/summary.html] Accessed on 1 February 2020.

4. Novel Coronavirus-China. [https://www.who.int/csr/don/12-january-2020-novel-coronavirus-china/en/]. Accessed on 1 February 2020.

5. Zhu N, et al. A Novel Coronavirus from Patients with Pneumonia in China, 2019. New England Journal of Medicine. 2020. [DOI: 10.1056/NEJMoa2001017]. 
6. Novel Coronavirus-Japan (ex-China). [https://www.who.int/csr/don/17-january-2020-novel-coronavirus-japan-ex-china/en/] Accessed on 1 February, 2020.

7. org. Novel 2019 Coronavirus Genome. [http://virological.org/t/novel-2019-coronavirus-genome/319]. Accessed on 1 February 2020.

8. Fehr AR, Channappanavar R, Perlman S. Middle East respiratory syndrome: emergence of a pathogenic human coronavirus. Annual review of medicine. 2017;68:387-99.

9. Statement on the second meeting of the International Health Regulations (2005) Emergency Committee regarding the outbreak of novel coronavirus (2019-nCoV). [https://www.who.int/news-room/detail/30-01-2020-statement-on-the-second-meeting-of-the-international-healthregulations-(2005)-emergency-committee-regarding-the-outbreak-of-novel-coronavirus-(2019-ncov)]. Accessed on 1 February 2020.

10. Arksey H, O’Malley L. Scoping studies: towards a methodological framework. International Journal of Social Research Methodology. 2005;8:19-32.

11. Moher D, et al. Preferred reporting items for systematic reviews and meta-analyses: the PRISMA statement. BMJ 2009;339:332-336

12. Zhou P, et al. Discovery of a novel coronavirus associated with the recent pneumonia outbreak in humans and its potential bat origin. bioRxiv [doi:https://doi.org/10.1101/2020.01.22.914952].

13. Li T, et al. Beijing Union Medical College Hospital on "pneumonia of novel coronavirus infection" diagnosis and treatment proposal (V2.0). Medical Journal of Peking Union Medical College Hospital. 2020, [http://kns.cnki.net/kcms/detail/11.5882.r.20200130.1430.002.html]. Accessed on 2 Feb 2020.

14. Medical expert group of Tongji hospital. Quick guide to the diagnosis and treatment of pneumonia for novel coronavirus infections (third edition). Herald of Medicine. 2020. [http://kns.cnki.net/kcms/detail/42.1293.r.20200130.1803.002.html]. Accessed on 2 February 2020.

15. Liu T, et al. Transmission dynamics of 2019 novel coronavirus (2019-nCoV). 2020. [doi: https://doi.org/10.1101/2020.01.25.919787].

16. Huang C, et al. Clinical features of patients infected with 2019 novel coronavirus in Wuhan, China. The Lancet. 2020. [https://doi.org/10.1016/ S0140-6736(20)30183-5].

17. Gralinski LE, Menachery VD. Return of the Coronavirus: 2019-nCoV. Viruses. 2020;12:135, https://doi.org/10.3390/v12020135.

18. Wang C, Wang X. Prevalence, nosocomial infection and psychological prevention of novel coronavirus infection. Chinese General Practice Nursing 2020;18.2-3. doi:10.12104/ j.issn.1674 4748.2020.03.02

19. National Health Commission of China. Prevent guideline of 2019-nCoV. 2020. [http://www.nhc.gov.cn/xcs/yqfkdt/202001/bc661e49b5bc487dba182f5c49ac445b.shtml]. Accessed on 1 February 2020.

20. National Health Commission of China. An update on the incidence of pneumonia with novel coronavirus infection as at 24:00 on 31 January 2020. http://www.nhc.gov.cn/xcs/yqfkdt/202002/84faf71e096446fdb1ae44939ba5c528.shtml (accessed on 1 February 2020).

21. Novel Coronavirus (2019-nCoV) Situation Report-11. 2020 [https://www.who.int/docs/default-source/coronaviruse/situationreports/20200131-sitrep-11-ncov.pdf?sfvrsn=de7c0f7_4]. Accessed on 1 February 2020.

22. Coronavirus. 2020. [https://www.who.int/health-topics/coronavirus] Accessed on 1 February 2020.

23. Su S, et al. Epidemiology, genetic recombination, and pathogenesis of coronaviruses. Trends in microbiology, 2016;24:490-502.

24. Chen Y, Liu Q, Guo D. Coronaviruses: genome structure, replication, and pathogenesis. Journal of Medical Virology, 2020, https://doi.org/10.1002/jmv.25681.

25. Peiris JS, Guan Y, Yuen K. Severe acute respiratory syndrome. Nature medicine 2004, 10, S88-S97. DOI: 10.1056/NEJMra032498.

26. Zaki AM et al. Isolation of a novel coronavirus from a man with pneumonia in Saudi Arabia. New England Journal of Medicine. 2012;367:1814-1820. DOI: 10.1056/NEJMoa1211721.

27. Chinese Center for Disease Control and Prevention detected 585 environmental samples from the South China Seafood Market in Wuhan, Hubei Province, China. [http://www.chinacdc.cn/yw_9324/202001/t20200127_211469.html] Accessed on 1 February 2020.

28. Lu H, Tang CW, Tang Y. Outbreak of Pneumonia of Unknown Etiology in Wuhan China: the Mystery and the Miracle. Journal of Medical Virology, 2020 DOI: https://doi.org/10/1002/jmv/25678.

29. Roujian L, et al. Genomic characterization and epidemiology of 2019 novel coronavirus: implications for virus origins and receptor binding. The Lancet 2020. https://doi.org/10.1016/ S0140-6736(20)30251-8,

30. Xu X, et al. Evolution of the novel coronavirus from the ongoing Wuhan outbreak and modeling of its spike protein for risk of human transmission. SCIENCE CHINA Life Sciences. 2020, https://doi.org/10.1007/s11427-020-1637-5

31. National Health Commission of China. Pneumonia diagnosis and treatment of 2019-nCoV infection from Chinese NHC and CDC 2020 [http://www.nhc.gov.cn/xcs/zhengcwj/202001/4294563ed35b43209b31739bd0785e67/files/7a9309111267475a99d4306962c8bf78.pdf]. Accessed on 1 February, 2020.

32. Zhang $\mathrm{H}$, et al. The digestive system is a potential route of 2019-nCov infection: a bioinformatics analysis based on single-cell transcriptomes. bioRxiv. 2020, doi: http://dx.doi.org/10.1101/2020.01.30.927806.

Page $9 / 13$ 
33. National Health Commission of China. Pneumonia infected with novel coronavirus is included in the management of legal infectious diseases. [http://www.nhc.gov.cn/jkj/s7915/202001/e4e2d5e6f01147e0a8df3f6701d49f33.shtml]. Accessed on 31 January, 2020.

34. National Health Commission of China. Notice on printing and distributing the technical guide for prevention and control of novel coronavirus infection in medical institutions. (First Edition) [http://www.nhc.gov.cn/yzygj/s7659/202001/b91fdab7c304431eb082d67847d27e14.shtml]. Accessed on 31 January, 2020.

35. National Health Commission of China. Notice on printing and distributing the work plan for prevention and control of pneumonia caused by novel coronavirus infection in the near future.[http://www.nhc.gov.cn/tigs/s7848/202001/808bbf75e5ce415aa19f74c78ddc653f.shtml]. Accessed on 31 January, 2020.

36. National Health Commission of China. Notice on further prevention and control of pneumonia caused by novel coronavirus infection in rural areas. 2020. [http://www.nhc.gov.cn/jkj/s3578/202001/f8d45f6af1d24ef18151c1d91cf8a028.shtml]. Accessed on 31 January, 2020.

37. National Health Commission of China. Notice on prevention and control of novel coronavirus infection pneumonia in the elderly people. [http://www.nhc.gov.cn/Iljks/tggg/202001/96e82ba8a14d41b283da990d39771493.shtml]. Accessed on 31 January, 2020.

38. Wei Q, Ren Z. Disinfection measures for pneumonia foci infected by novel coronavirus in 2019. Chinese journal of Disinfection. 2020;37:5962.

39. Bin C, Fang X, Chen $\mathrm{H}$. Application effect of disaster vulnerability analysis in coping with the transmission of new coronavirus in non-closed hematology ward. [http://kns.cnki.net/kcms/detail/14.1272.R.20200131.1909.002.html]. Accessed on 2 Feb 2020.

40. Xu M, Zhang Y. Investigation on the psychological status of the first batch of clinical first-line support nurses to fight against pneumonia caused by novel coronavirus. Chinese Nursing Research. 2020;34:1-3.

41. Ou F, et al. Countermeasures for rapid spread of new coronavirus pneumonia in Wuhan. Chinese General Practicing Nursing. [http://kns.cnki.net/kcms/detail/14.1349.R.20200131.1319.002.html]. Accessed on 2 February 2020.

42. Advice on the use of masks in the community, during home care and in health care settings in the context of the novel coronavirus 2019nCoV outbreak (Interim guidance). [WHO/nCov/IPC_Masks/2020.1] Accessed on 3 February 2020.

43. National Health Commission, China. Guidelines for public protection against novel coronavirus infection. [http://www.nhc.gov.cn/jkj/s7915/202001/bc661e49b5bc487dba182f5c49ac445b.shtml]. Accessed 31 January, 2020.

\section{Figures}




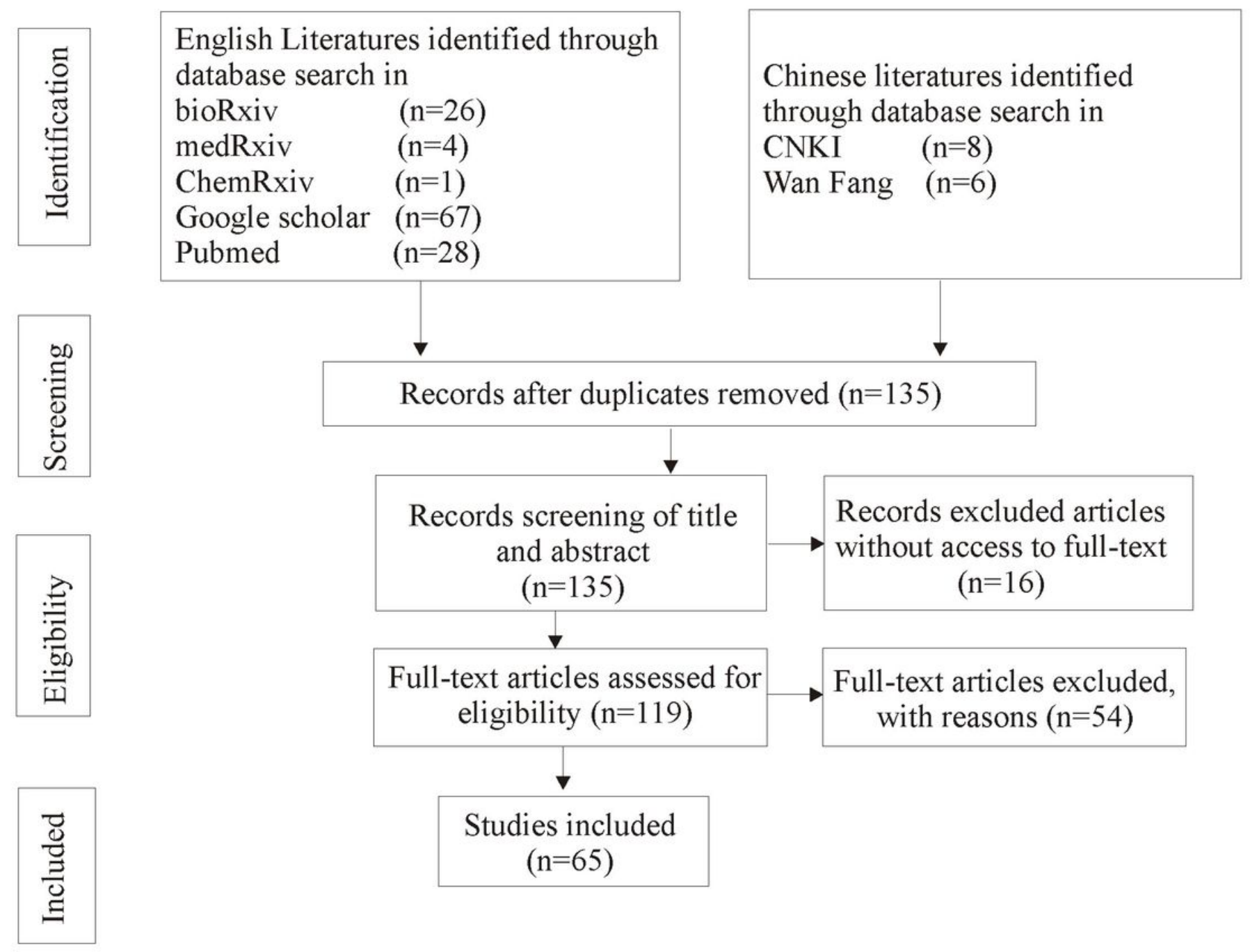

Figure 1

PRISMA Flow Diagram for the scoping review process

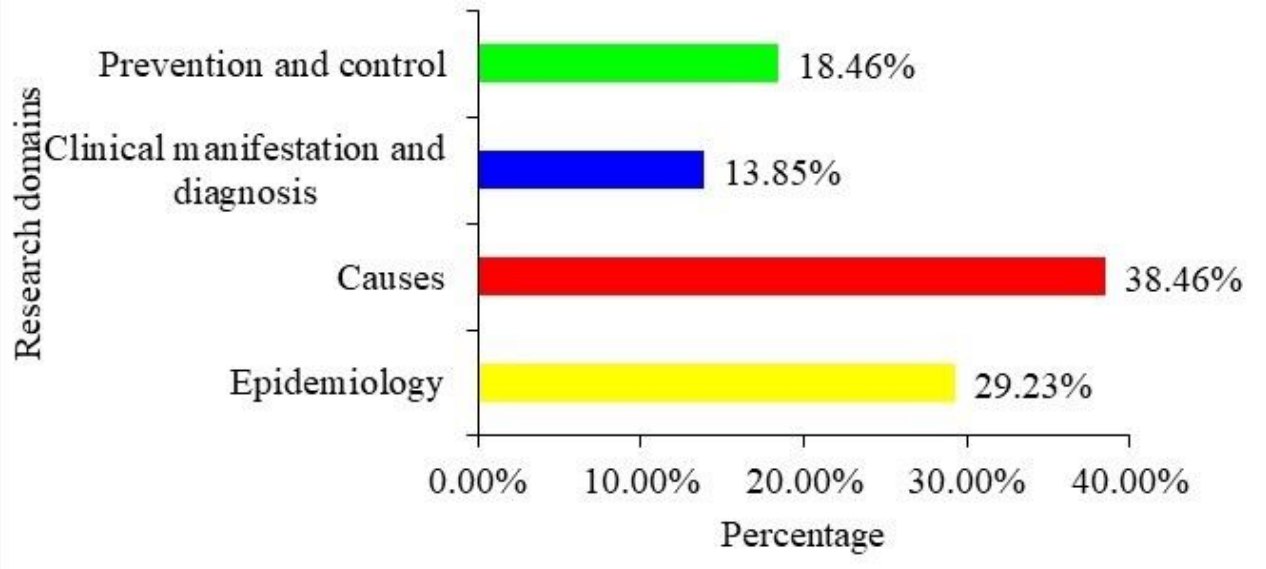

Figure 2

Percentage of published research articles 


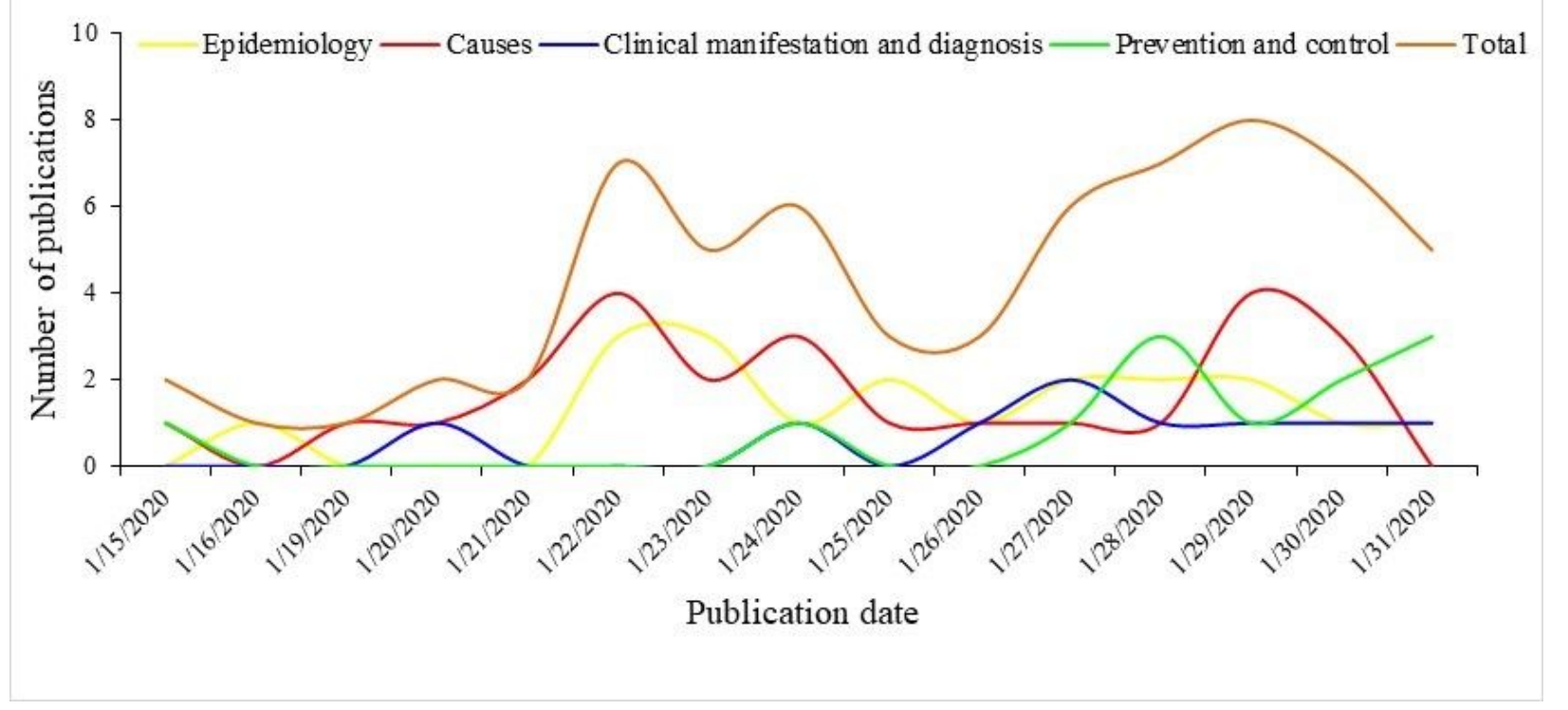

Figure 3

Publication of research articles according to date

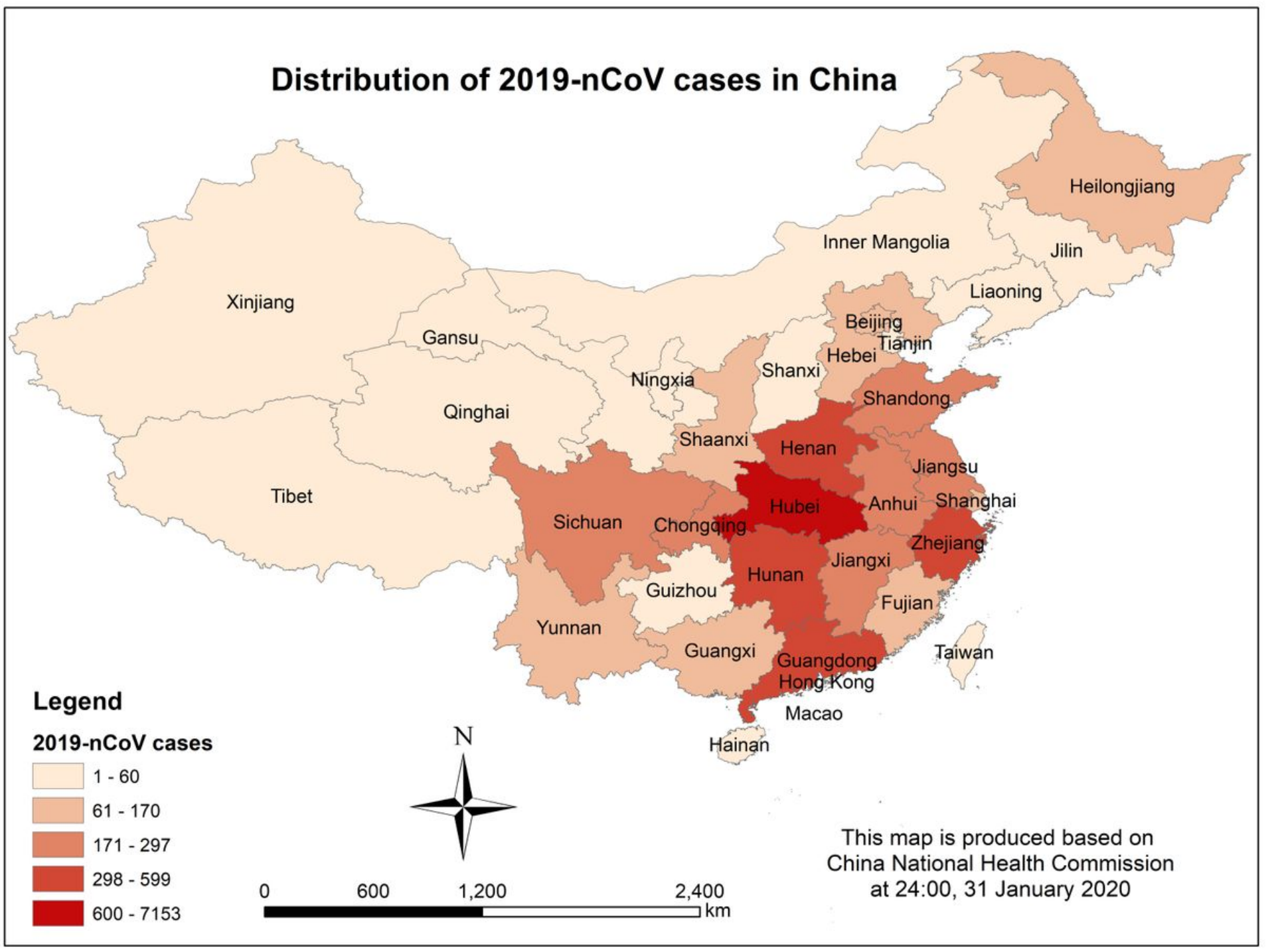



expression of any opinion whatsoever on the part of Research Square concerning the legal status of any country, territory, city or area or of its authorities, or concerning the delimitation of its frontiers or boundaries. This map has been provided by the authors.

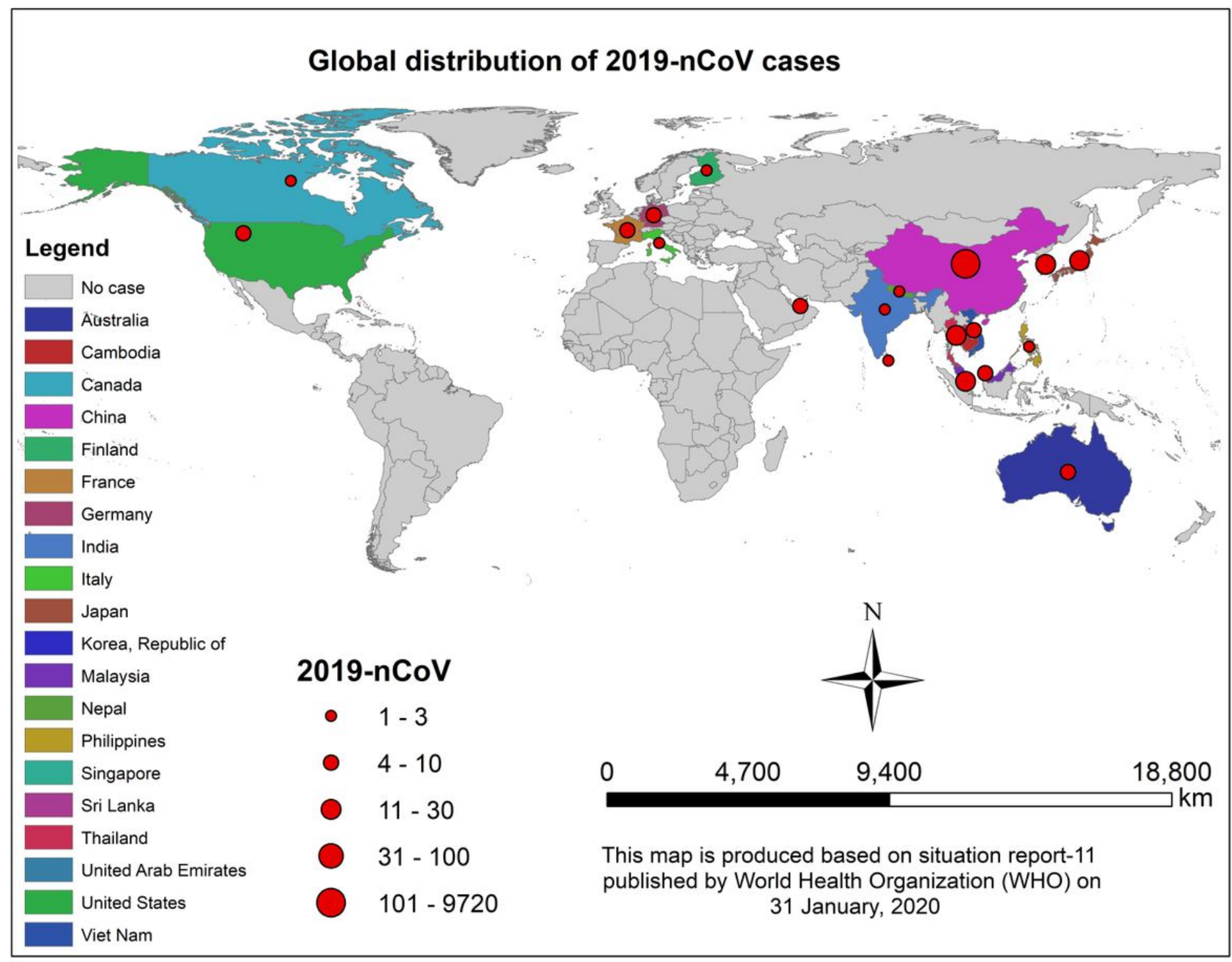

Figure 5

Global distribution of 2019-nCoV cases. Note: The designations employed and the presentation of the material on this map do not imply the expression of any opinion whatsoever on the part of Research Square concerning the legal status of any country, territory, city or area or of its authorities, or concerning the delimitation of its frontiers or boundaries. This map has been provided by the authors.

\section{Supplementary Files}

This is a list of supplementary files associated with this preprint. Click to download.

- AppendixTable.docx 